\title{
Effects of Lithium and Valproic Acid on the Production of Brain-Derived Neurotrophic Factor in Astrocytoma
}

\author{
Koji Ohtomo ${ }^{1,2}$, Satoshi Nishino ${ }^{3,4}$, Masatake Kurita ${ }^{3,4}$, Hirobumi Mashiko ${ }^{{ }^{*} \text {, }}$ \\ Shin-ichi Niwa ${ }^{1}$ \\ ${ }^{1}$ School of Medicine, Department of Neuropsychiatry, Fukushima Medical University, Fukushima, Japan \\ ${ }^{2}$ Izuka Hospital, Fukushima, Japan \\ ${ }^{3}$ Department of Cellular Signaling, Graduate School of Pharmaceutical Sciences, Tohoku University, Sendai, \\ Japan \\ ${ }^{4}$ Sato Hospital, Yamagata, Japan \\ Email: ${ }^{*}$ mashiko@fmu.ac.jp
}

Received 2 May 2014; revised 30 May 2014; accepted 25 June 2014

Copyright (C) 2014 by authors and Scientific Research Publishing Inc.

This work is licensed under the Creative Commons Attribution International License (CC BY).

http://creativecommons.org/licenses/by/4.0/

(c) (i) Open Access

\section{Abstract}

No systematic investigation considering BDNF and its receptor TrkB has been conducted on the effects of mood-stabilizing drugs. We therefore decided to quantify BDNF production and the expression of TrkB-T1 receptor and PLC $\gamma$ in astrocytoma. 1321N human astrocytoma cells were grown to a sufficient quantity in $5 \%$ fetal calf serum (FCS). The mood-stabilizing drugs Li and VPA were added to the therapeutic concentrations of $1 \mathrm{mM}$ and $600 \mu \mathrm{M}$, respectively. The production of BDNF was determined by an enzyme-linked immunosorbent assay. The expressions of TrkB-T1 and PLC $\gamma$ were determined by Western blot. The production of BDNF was significantly higher on Day 7 in the VPA samples $(P<0.05)$ and was significantly suppressed beginning on Day 1 in the Li samples $(P<0.05)$. TrkB-T1 expression, in contrast to BDNF production, was significantly higher in the VPA samples $(\mathrm{P}<0.05)$ but did not change in the Li samples. PLC $\gamma$ expression did not change. $\mathrm{Li}$ and VPA seem differently affect BDNF production and TrkB-T1 (BDNF receptor) expression.

\section{Keywords}

BDNF, Bipolar Disorder, Lithium, PLC $\gamma$, TrkB, Valproic Acid

\footnotetext{
${ }^{*}$ Corresponding author.
}

How to cite this paper: Ohtomo, K., Nishino, S., Kurita, M., Mashiko, H. and Niwa, S. (2014) Effects of Lithium and Valproic Acid on the Production of Brain-Derived Neurotrophic Factor in Astrocytoma. Open Journal of Psychiatry, 4, 261-268. 


\section{Introduction}

Bipolar disorder, a manic-depressive disease, persists throughout life in $0.8 \%$ of those afflicted [1]. Refractory to treatment, bipolar disorder often recurs repeatedly. This serious disease is sometimes marked by rapid cycling between manic-depressive episodes, which hinders the social activities of patients. Tsuang and Winokur claim that $15 \%$ of patients have a good prognosis, $45 \%$ suffer repeated recurrences, $30 \%$ experience partial remission, and $10 \%$ develop a chronic form of the disease [2].

Mood stabilizing drugs, and particularly lithium (Li) and valproic acid (VPA), are the primary treatment for bipolar disorder. Lithium was first shown to be effective in bipolar disorder by Schou et al., and is still a firstline treatment [3]. Lithium acts by blocking inositol monophosphatase (IMPase) to deplete inositol levels and thereby induce inositol phosphate desensitization [4]. The inhibition of the serine-threonine kinase GSK-3 $\beta$, which controls synaptic plasticity and apoptosis [5], and the increases in bcl-2, a signal transduction molecule responsible for neurogenesis and protection [6], have received recent focus as likely mechanisms of action. Valproic acid is also widely used in treatment. The mechanism of VPA shares commonalities with $\mathrm{Li}$, such as its actions on the inositol phospholipids and effects on GSK-3 $\beta$ and bc1-2 [7], but there is a paucity of data to assist with the selection of mood-stabilizing drugs in the clinic because many aspects of the mechanisms of action of these two mood-stabilizing drugs remain unclear.

Recent research has established a link between depression and brain-derived neurotrophic factor (BDNF). The most plentiful neurotrophic factor in the brain, BDNF maintains nerve growth, regulates neurotransmitter levels, and plays an important role in learning, memory, and other elements of neuroplasticity. In patients with depression, serum BDNF levels decrease in proportion to disease severity and normalize in proportion to the degree of symptom improvement achieved with antidepressant therapy [8]. The number of nerve cells in the hippocampal region decreases in depression. This decline is reversed and symptoms improve with antidepressant therapy [9], so increasing BDNF levels accompanying antidepressant therapy is thought to promote neurogenesis and thereby alleviate depression. It has been suggested that BDNF-associated neurogenesis and neuroprotection contribute substantially to the pathophysiology of bipolar disorder [10].

A link between mood disorders and astrocytes is being increasingly claimed as knowledge about not only nerve cells but also glial cells and particularly astrocytes grows. Astrocytes outnumber nerve cells ten to one in the brain, where they provide a physical support for nerve cells and form the blood-brain barrier. Astrocytes also regulate neurotransmitter levels in synaptic clefts, produce BDNF, provide relief during cerebral ischemia, and contribute to the pathology of neurodegenerative diseases. Patients with mood disorders have a significantly lower number of glial cells in the prefrontal cortex and amygdale [11] [12], which strongly suggests that reduced glial function is related to mood disorders.

Lithium, VPA, and several other mood-stabilizing drugs are first-line therapies for patients with bipolar disorder, but no systematic research covering BDNF, its receptor, and secondary messengers has been conducted on their mechanism of action and particularly on the effects on astrocytes. Elucidating the effects of mood-stabilizing drugs on astrocytes would provide new data to unlock the mysteries of bipolar disorder pathogenesis and allow clinicians to better select therapeutic drugs based on BDNF levels of their patients in the clinic. This research, with a focus on BDNF, its receptor, and secondary messengers, analyzes BDNF production and the expression of the TrkB-T1 receptor and PLC $\gamma$ in 1321N1 human astrocytoma treated with therapeutic concentrations of the mood-stabilizing drugs Li and VPA.

\section{Methods}

\subsection{Drugs Used}

Sodium valproate (VPA) was kindly donated by Kyowa Hakko Kogyo Co., Ltd. (Tokyo, Japan), and lithium chloride (Li) was purchased from Wako Pure Chemical Industries, Ltd. (Osaka, Japan).

\subsection{Cell Culture}

1321N1 human astrocytoma cells were cultured in Dulbecco's modified Eagle medium containing 5\% fetal calf serum (FCS), $50 \mathrm{U} / \mathrm{mL}$ penicillin, and $5 \mu \mathrm{g} / \mathrm{mL}$ streptomycin inside an incubator maintained at $37^{\circ} \mathrm{C}, 5 \% \mathrm{CO}_{2}$, and $95 \%$ air. After the cells were cultured for an appropriate time, the medium was replaced with medium lacking FCS. The cells were treated with Li diluted to a concentration of $1 \mathrm{mM}$ and VPA diluted to a concentration 
of $600 \mu \mathrm{M}$.

\subsection{BDNF Protein Measurement}

1321N1 astrocytoma cells were treated with Li and VPA. Culture medium supernatant was collected on Days 1, 3,5 , and 7 and stored at $-80^{\circ} \mathrm{C}$ until analysis. The BDNF Emax ${ }^{\circledR}$ immunoassay system by Promega (Madison, WI, USA) was used to measure BDNF protein levels. Anti-BDNF monoclonal antibodies were diluted by a factor of 1000 in carbonate coating buffer, and $100 \mu \mathrm{L}$ was added into Nunc MaxiSorp ${ }^{\mathrm{TM}}$ (Nunc, Roskilde, Denmark) 96-well enzyme-linked immunosorbent assay plates, which were then incubated overnight at $4^{\circ} \mathrm{C}$. The carbonate coating buffer was discarded, and the wells were washed with tris-buffered saline (pH 7.5) with 0.05\% Tween 20 (TBST) wash buffer and then blocked for 1 hour at room temperature with block and sample buffer. The BDNF standard was diluted by a factor of 2000 with block and sample buffer and a 7-step serial dilution was prepared over the concentration range of $500 \mathrm{pg} / \mathrm{mL}$ to $7.5 \mathrm{pg} / \mathrm{mL}$. The wells in two columns were analyzed in duplicate to prepare a standard curve. Then the samples were added to the wells and shaken at room temperature for 2 hours. The wells were washed five times with TBST. Anti-human BDNF polyclonal antibodies were diluted by a factor of 500 with block and sample buffer and then added to each well. The plates were shaken at room temperature for 2 hours. The wells were then washed five times with TBST. Next, anti-IgY labeled with horseradish peroxidase was added. The wells were shaken for 1 hour at room temperature and then washed five times with TBST. Finally, a chromagen substrate (3,3',5,5'-tetramethylbenzidine; TMB) solution was added to each well. The wells were shaken at room temperature for 10 minutes, the reaction was quenched with $1 \mathrm{~N}$ hydrochloric acid, and absorbance $(450 \mathrm{~nm})$ was measured with a microplate reader (Bio-Rad Laboratories, Hercules, CA, USA).

\subsection{Western Blot}

Protein levels were determined by the Western blot method because TrkB-T1, PLC $\gamma$, and the internal standard GADPH, whose expression is constant, were used. As in the BDNF measurement, 1321N1 astrocytoma cells treated for 1, 3, 5, and 7 days with Li and VPA were collected, lysed in a lysis buffer, and centrifuged. The supernatant was collected and protein quantification was conducted with the Lowry method to achieve a level of $30 \mu \mathrm{g}$. To the analyzed samples was added buffer for sodium dodecylsulfate (SDS) treatment [225 mM tris-HCl buffer (pH 6.8) containing 30\% glycerol, 6\% SDS, 0.009\% bromophenol blue, 9\% 2-mercaptoethanol] at a volumetric ratio of 2:1. The samples were boiled at $100^{\circ} \mathrm{C}$ for 10 minutes. Following SDS treatment, the samples were subjected to electrophoresis ( $35 \mathrm{~mA} /$ plate) at room temperature on polyacrylamide gel ( $3 \%$ concentrating gel and $8 \%$ separating gel). After electrophoresis, the gel was blotted at $120 \mathrm{~mA}$ for 90 minutes on a polyvinylidene difluoride (PVDF) membrane activated with 100\% methanol. This was followed by blocking overnight with $5 \%$ skim milk dissolved in $10 \mathrm{mM}$ Tris-HCl buffer (pH 7.5) containing $100 \mathrm{mM} \mathrm{NaCl}$ and $0.1 \%$ Tween 20). The PVDF membrane was diluted 500-, 1000-, and 2000-fold with 3\% skim milk (dissolved in TBST) and allowed to react for 2 hours at room temperature with TrkB-T1 antibody, PLC $\gamma$ antibody, and GAPDH (glyceraldehyde-3-phosphate dehydrogenase) antibody as primary antibodies and then washed five times for 5 minutes each time with TBST. The gel was then reacted with peroxidase-labeled anti-mouse IgG antibody or anti-rabbit IgG antibody diluted with 3\% skim milk (dissolved in TBST) as the secondary antibodies for 1 hour at room temperature and then washed five times for 5 minutes each time with TBST. The PVDF membrane was then reacted for 1 minute with ECL ${ }^{\mathrm{TM}}$ Detection Reagent (GE Healthcare, Buckinghamshire, England). X-ray film was then exposed to detect an antibody-positive blot. The X-ray film was developed and scanned into a computer. Protein expression was then quantified with the image analysis application Image-J software (National Institutes of Health, Bethesda, MD, USA).

\subsection{Data Analysis}

The data presented in this dissertation are expressed as mean \pm standard deviation (mean \pm S.D.). The TrkB-T1 and PLC $\gamma$ data obtained by the Western blot method were corrected with GAPDH as the internal standard and are expressed relative to the control, which has a value of 1 . Values were compared using one-way analysis of variance, and Scheffe's $\mathrm{F}$ test was used as a post hoc test. P values less than 0.05 were taken to constitute statistical significance. 


\section{Results}

\subsection{Effects of Li and VPA on BDNF Production}

Changes over time in BDNF production following treatment with $1 \mathrm{mM} \mathrm{Li}$ and $600 \mu \mathrm{M}$ VPA are shown in Figure 1. The production of BDNF did not differ in the control and VPA samples to Day 5, but was significantly suppressed from Days 1 to 7 in the Li samples ( $<$ 0.05). Production was significantly higher in the VPA solution than the control on Day 7 ( $<<0.05)$.

\subsection{Effects of Li and VPA on TrkB-T1 Expression}

The expression of TrkB-T1 in the groups did not differ on Day 1 (Figure 2), but was significantly higher in the VPA group beginning on Day $3(\mathrm{p}<0.05)$. Western blots on Day 7 are shown in Figure 3. Expression in the Li group was comparable to that in the control (Figure 4).

\subsection{Effects of Li and VPA on PLC $\gamma$ Expression}

Lithium and VPA treatment did not result in a difference in PLC $\gamma$ expression at any time point (Figure 5).

\section{Discussion}

Authors believe this research to be the first investigation quantifying BDNF production as well as TrkB-T1 and PLC $\gamma$ expression in 1321N1 human astrocytoma cells treated with Li and VPA, because the literature lacks mention of any previous study systematically comparing BDNF, its receptor, and secondary messengers. This research is also the first to mention different actions of Li and VPA except our previous report [13].

Relative to the control, Li significantly suppressed BDNF production but did not significantly change the ex-

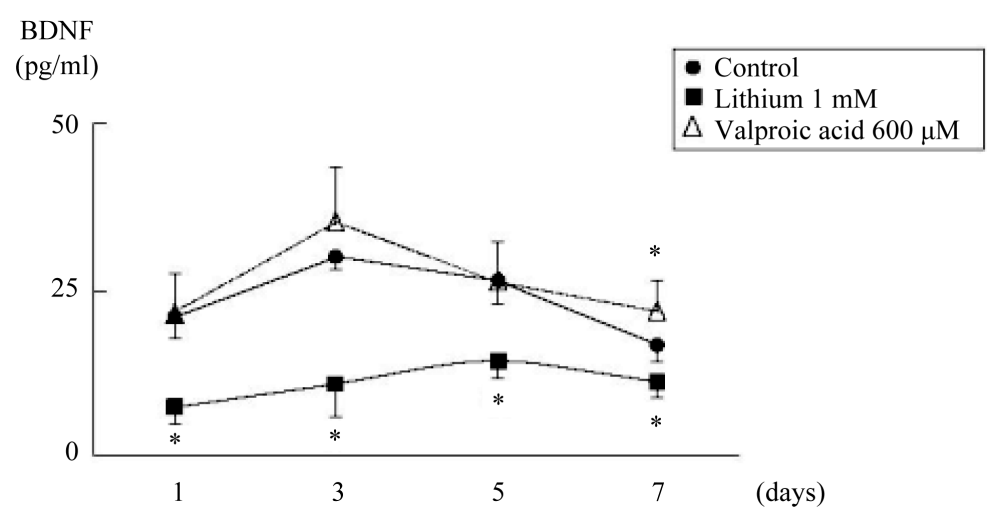

Figure 1. Effect of VPA $(600 \mu \mathrm{M})$ or Li $(1 \mathrm{mM})$ on BDNF level in human astrocytoma $1321 \mathrm{~N} 1$ cells. Cells were treated with VPA $(600 \mu \mathrm{M})$ or $\mathrm{Li}(1 \mathrm{mM})$ and incubated for 7 days. BDNF levels were measured by immunoassay. Each column represents the mean \pm S.D. of experiments $(n=5-6)$. Statistically significant differences were calculated using ANOVA with a post-hoc Scheffe test $\left({ }^{*} \mathrm{p}<0.05\right)$.

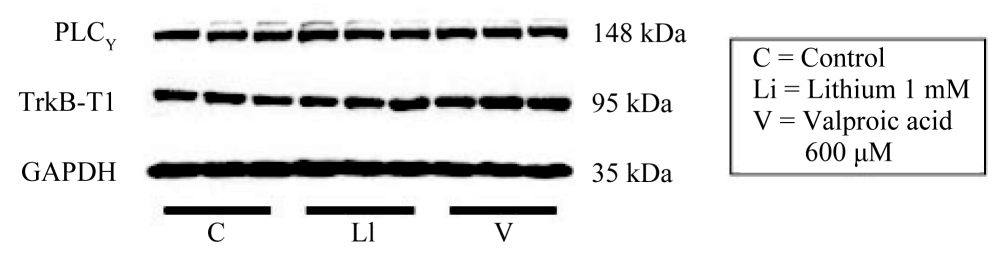

Figure 2. Effect of VPA $(600 \mu \mathrm{M})$ or Li $(1 \mathrm{mM})$ on BDNF level in human astrocytoma $1321 \mathrm{~N} 1$ cells. Cells were treated with VPA $(600 \mu \mathrm{M})$ or $\mathrm{Li}(1 \mathrm{mM})$ and incubated for 1 day. PLC $\gamma$ or TrkB-T1 levels were demonstrated by Western blot method with GAPDH as an internal control. 


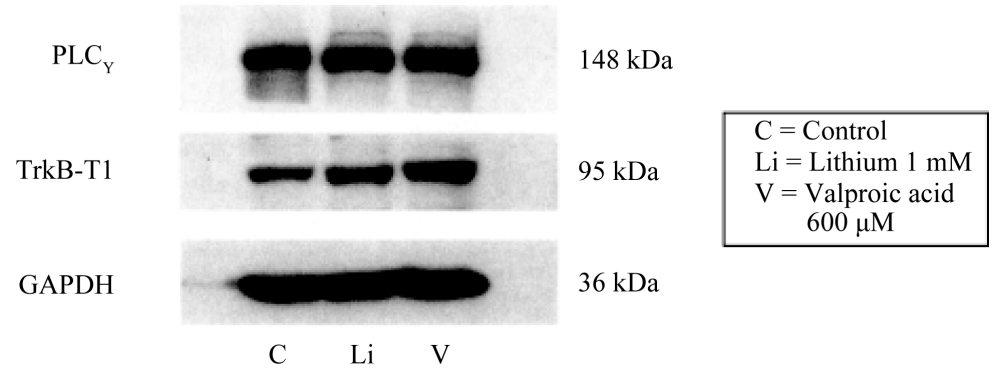

Figure 3. Effect of VPA $(600 \mu \mathrm{M})$ or Li $(1 \mathrm{mM})$ on BDNF level in human astrocytoma $1321 \mathrm{~N} 1$ cells. Cells were treated with VPA $(600 \mu \mathrm{M})$ or Li $(1 \mathrm{mM})$ and incubated for 7 days. PLC $\gamma$ or TrkB-T1 levels were demonstrated by Western blot method with GAPDH as an internal control.

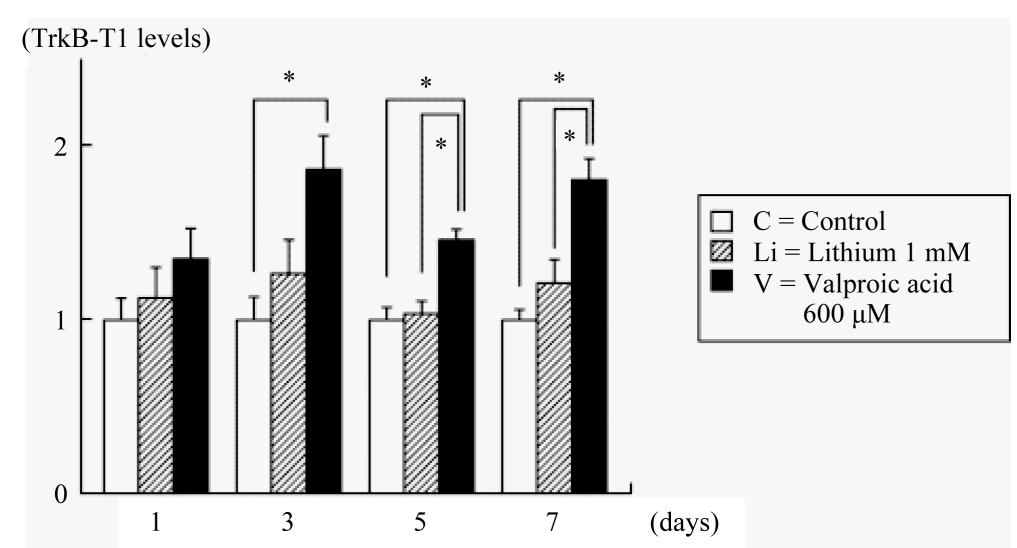

Figure 4. Effect of VPA $(600 \mu \mathrm{M})$ or Li $(1 \mathrm{mM})$ on TrkB-T1 level in human astrocytoma $1321 \mathrm{~N} 1$ cells. Cells were treated with VPA $(600 \mu \mathrm{M})$ or Li $(1 \mathrm{mM})$ and incubated for 7 days. TrkB-T1 levels were measured by immunoassay. Each column represents the mean \pm S.D. of experiments $(n=5-6)$. Statistically significant differences were calculated using ANOVA with a post-hoc Scheffe test $(* \mathrm{p}<0.05)$.

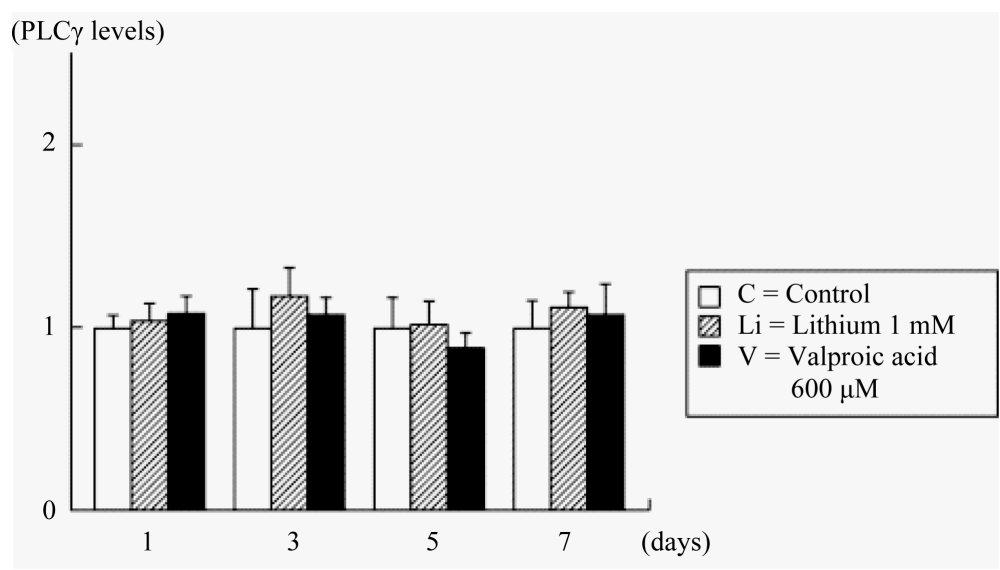

Figure 5. Effect of VPA $(600 \mu \mathrm{M})$ or Li $(1 \mathrm{mM})$ on PLC $\gamma$ level in human astrocytoma $1321 \mathrm{~N} 1$ cells. Cells were treated with VPA $(600 \mu \mathrm{M})$ or $\mathrm{Li}(1 \mathrm{mM})$ and incubated for 7 days. PLC $\gamma$ levels were measured by immunoassay. Each column represents the mean \pm S.D. of experiments $(n=5-6)$. Statistically significant differences were calculated using ANOVA with a post-hoc Scheffe test (*p < 0.05). 
pression of PLC $\gamma$ or TrkB-T1 receptor. Valproic acid did not significantly change BDNF production to Day 5, but production was significantly higher than in the control on Day 7. The expression of TrkB-T1 receptor was significantly higher beginning on Day 3. As in the Li samples, PLC $\gamma$ expression did not differ significantly from that in the control. These findings show that Li and VPA have different effects on BDNF production and TrkB$\mathrm{T} 1$ receptor expression in astrocytoma cells.

The BDNF receptor TrkB is known to exist as the following two types [14]: full-length catalytic TrkB (145 $\mathrm{kDa}$ ) known as TrkB-FL and the truncated form of TrkB (95kDa) that lacks the tyrosine kinase domain. Neurons express primarily TrkB-FL while astrocytes primarily express the TrkB-T1 truncated form, which lacks the kinase domain. Astrocytes express 100 times more TrkB-T1 than TrkB-FL. PLC $\gamma$ is known to react downstream of the TrkB-FL receptor, but the PLC subtype of TrkB-T1 remains unknown [14]. Lithium and VPA did not change PLC $\gamma$ expression, which rules out a contribution of PLC $\gamma$. The differences in the BDNF data in this research may be indicative of differences in TrkB-T1 receptor and TrkB-FL functionality.

In a study in the rat brain, $\mathrm{Li}$ increased BDNF in the frontal lobe, parietal lobe, and hippocampus, VPA increased BDNF in the frontal lobe and hippocampus, and TrkB receptor expression was unchanged [15]. In our research on astrocytoma cells, Li significantly suppressed BDNF and VPA significantly increased BDNF on Day 7 relative to the control. The rat brain findings differ from our findings in astrocytoma cells in terms of Li effects. In our experimental model [16]-[18], measurements were taken without neurotrophic factors acting on the astrocytes by not adding FCS to the cultured cells in order to eliminate their effects on BDNF measurements. Measurements beyond Day 7 were not possible because of dwindling cell numbers, because the cultured cells are unable to survive long without FCS. Functional differences in nerve cells and astrocytes prevent the comparison of individual differences, but it should be noted that in primary cultured rat neurons grown in FCS-free medium, treatment with $1 \mathrm{mM} \mathrm{Li}$ increased BDNF production on Day 3 but lowered production on Day 5 [19]. Differences in the type of experimental system may be responsible for the differences from the findings in rat brain.

In the VPA samples, BDNF production was significantly higher than in the control on Day 7 and VPA also increased TrkB-T1 expression in astrocytes, which indicates its mechanism of action may differ from that of Li. A time-dependent increase in BDNF mRNA was seen 12 and 24 hours after cultured C6 glioma cells were treated with VPA in another study [20]. This finding provides support to our data.

Lithium was first shown to be effective in bipolar disorder by Schou et al. [3] and is still a widely used moodstabilizing drug. Plentiful evidence supports its use. Lithium is thought to act on inositol phospholipids as well as GSK-3 $\beta$ and bc1-2, but many uncertainties surround its mechanism of action. Little data are available to guide choices of mood-stabilizing drugs in the clinic. Some doctors attempt a variety of drugs when administering treatment, requiring substantial time to stabilize symptoms. The elucidation of the specific mechanisms of action of Li and VPA would help doctors considering mood-stabilizing drug options and also help with the selection of multi-drug regimens. Confirmation that their mechanisms of action differ would be an important finding for the clinical use of mood-stabilizing drugs.

Our research on changes in BDNF, TrkB-T1, and PLC $\gamma$ in astrocytoma cells treated with Li and VPA has provided excellent reference data for the selection of mood-stabilizing drugs in the clinic. Findings regarding BDNF are conflicting: BDNF has often been shown to be low in patients with depression and has also been found to be low in untreated manic patients with bipolar disorder [21], but elevated in the hippocampal mossy fiber of the postmortem brains of patients with bipolar disorder [22]. Mood-stabilizing drugs are thought to act not only on BDNF but also a variety of other factors including neurogenesis, neuroplasticity, and cell survival in the hippocampus. Lithium and VPA are both known to have these effects. Although many studies have indicated the commonalities in the mechanisms of action of mood-stabilizing drugs, we believe this dissertation to be the first report of mechanistic differences. Although neurotrophic factors hold great promise for disease treatment, issues surrounding drug delivery and maintaining therapeutically effective concentrations hinder clinical application. Therapeutic and pathologic research using astroglial cells is an important research field, which substantially elucidates the mechanism of mood disorder treatments in terms of effects of neurotrophic factors. And our discovery of differences in the effects of the two mood-stabilizing drugs will contribute to the future treatments. Our research investigated BDNF, TrkB-T1, and PLC $\gamma$ in astrocytes. Further investigation of variation in and the activity of other secondary messengers downstream of the TrkB-T1 receptor could further elucidate the mechanisms of action of Li and VPA. Additionally, a study of detailed BDNF expression in patients in the clinic and changes in BDNF following treatment with mood-stabilizing drugs could yield more detailed findings. 
In view of the difference between the action of $\mathrm{Li}$ and that of VPA in this study, the authors aimed to detect the difference during 1 week incubation period, which is relevant to the acute effect of the drugs. As a result, the potency of VPA was assumed to be higher than that of $\mathrm{Li}$ in during this incubation period consistent to a clinical practice of acute phase of manic state. Subsequently the difference of the potency during the following period should be elucidated. The measurement of mRNA of the surveyed proteins would be useful to clarify the question.

\section{Conclusion}

We investigated BDNF production and the expression of TrkB-T1 (BDNF receptor) and PLC $\gamma$ in cultured astrocytoma cells treated with therapeutic concentrations of $\mathrm{Li}$ and VPA. In the Li-treated samples, TrkB-T1 and PLC $\gamma$ expression was unaffected while BDNF production was significantly suppressed. In the VPA-treated samples, PLC $\gamma$ expression was unchanged while BDNF production and TrkB-T1 expression were significantly elevated. Lithium and VPA disparately affected BDNF production and TrkB-T1 (BDNF receptor) expression.

\section{Acknowledgements}

None.

\section{References}

[1] Bourdon, K.H., Rae, D.S., Locke, B.Z., Narrow, W.E. and Regier, D.A. (1992) Estimating the Prevalence of Mental Disorders in US Adults from the Epidemiologic Catchment Area Survey. Public Health Reports, 107, 663-668.

[2] Tsuang, M.T. and Winokur, G. (1975) The Iowa 500: Field Work in a 35-Year Follow-Up of Depression, Mania, and Schizophrenia. Canadian Psychiatric Association Journal, 20, 359-365.

[3] Schou, M., Juel-Nielsen, N., Stromgrene, E. and Voldby, H. (1954) The Treatment of Manic Psychoses by the Administration of Lithium Salts. Journal of Neurology, Neurosurgery and Psychiatry, 17, 250-260. http://dx.doi.org/10.1136/jnnp.17.4.250

[4] York, J.D., Ponder, J.W. and Majerus, P.W. (1995) Definition of A Metal-Dependent/Li(+)-Inhibited Phosphomonoesterase Protein Family Based upon a Conserved Three-Dimensional Core Structure. Proceedings of the National Academy of Sciences of the United States of America, 92, 5149-5153. http://dx.doi.org/10.1073/pnas.92.11.5149

[5] Gould, T.D., Zarate, C.A. and Manji, K. (2004) Glycogen Synthase Kinase-3: A Target for Novel Bipolar Disorder Treatments. Journal of Clinical Psychiatry, 65, 10-21. http://dx.doi.org/10.4088/JCP.v65n0103

[6] Chuang, D.M., Chen, R.W., Chalecka-Franaszek, E., Ren, M., Hashimoto, R., Senatorov, V., Kanai, H., Hough, C., Hiroi, T. and Leeds, P. (2002) Neuroprotective Effects of Lithium in Cultured Cells and Animal Models of Diseases. Bipolar Disorders, 4, 129-136. http://dx.doi.org/10.1034/j.1399-5618.2002.01179.x

[7] Williams, R.S., Cheng, L., Mudge, A.W. and Harwood, A.J. (2002) A Common Mechanism of Action for Three Mood-Stabilizing Drugs. Nature, 417, 292-295. http://dx.doi.org/10.1038/417292a

[8] Shimizu, E., Hashimoto, K., Okamura, N., Koike, K., Komatsu, N., Kumakiri, C., Nakazato, M., Watanabe, H., Shinoda, N., Okada, S. and Iyo, M. (2003) Alterations of Serum Levels of Brain-Derived Neurotrophic Factor (BDNF) in Depressed Patients with or without Antidepressants. Biological Psychiatry, 54, 70-75. http://dx.doi.org/10.1016/S0006-3223(03)00181-1

[9] Malberg, J.E., Eisch, A.J., Nestler, E.J. and Duman, R.S. (2000) Chronic Antidepressant Treatment Increases Neurogenesis in Adult Rat Hippocampus. Journal of Neuroscience, 20, 9104-9110.

[10] Shaltiel, G., Chen, G. and Manji, H.K. (2007) Neurotrophic Signaling Cascades in the Pathophysiology and Treatment of Bipolar Disorder. Current Opinion in Pharmacology, 7, 22-26. http://dx.doi.org/10.1016/j.coph.2006.07.005

[11] Rajkowska, G. (2000) Postmortem Studies in Mood Disorders Indicate Altered Numbers of Neurons and Glial Cells. Biological Psychiatry, 48, 766-777. http://dx.doi.org/10.1016/S0006-3223(00)00950-1

[12] Bowley, M.P., Drevets, W.C., Ongür, D. and Price, J.L. (2002) Low Glial Numbers in the Amygdala in Major Depressive Disorder. Biological Psychiatry, 52, 404-412. http://dx.doi.org/10.1016/S0006-3223(02)01404-X

[13] Nishino, S., Ohtomo, K., Numata, Y., Sato, T., Nakahata, N. and Kurita, M. (2012) Divergent Effects of Lithium and Sodium Valproate on Brain-Derived Neurotrophic Factor (BDNF) Production in Human Astrocytoma Cells at Therapeutic Concentrations. Progress in Neuro-Psychopharmacology and Biological Psychiatry, 39, 17-22. http://dx.doi.org/10.1016/j.pnpbp.2011.07.008

[14] Blum, R. and Konnerth, A. (2005) Neurotrophin-Mediated Rapid Signaling in the Central Nervous System: Mechan- 
isms and Functions. Physiology (Bethesda), 20, 70-78. http://dx.doi.org/10.1152/physiol.00042.2004

[15] Fukumoto, T., Morinobu, S., Okamoto, Y., Kagaya, A. and Yamawaki, S. (2001) Chronic Lithium Treatment Increases the Expression of Brain-Derived Neurotrophic Factor in the Rat Brain. Psychopharmacology, 158, 100-106. http://dx.doi.org/10.1007/s002130100871

[16] Kurita, M., Mashiko, H., Ogata, M., Kumasaka, T., Niwa, S., Nakahata, N., Takano, S. and Nakanishi, H. (2000) Discrimination of Histamine H1 and Muscarinic Receptor-Mediated Signalling Pathways by Phorbol Ester in Human Astrocytoma Cells. Clinical and Experimental Pharmacology and Physiology, 27, 208-211. http://dx.doi.org/10.1046/j.1440-1681.2000.03227.x

[17] Kurita, M., Mashiko, H., Rai, M., Kumasaka, T., Kouno, Si., Niwa, Si. and Nakahata, N. (2002) Lithium Chloride at a Therapeutic Concentration Reduces Ca2+ Response in Protein Kinase C Down-Regulated Human Astrocytoma Cells. European Journal of Pharmacology, 442, 17-22. http://dx.doi.org/10.1016/S0014-2999(02)01491-7

[18] Kurita, M., Nishino, S., Ohtomo, K., Rai, M., Shirakawa, H., Mashiko, H., Niwa, S. and Nakahata, N. (2007) Sodium Valproate at Therapeutic Concentrations Changes $\mathrm{Ca}^{2+}$ Response Accompanied with Its Weak Inhibition of Protein Kinase C in Human Astrocytoma Cells. Progress in Neuro-Psychopharmacology and Biological Psychiatry, 31, 600604. http://dx.doi.org/10.1016/j.pnpbp.2006.11.019

[19] Hashimoto, R., Takei, N., Shimazu, K., Christ, L., Lu, B. and Chuang, D.M. (2002) Lithium Induces Brain-Derived Neurotrophic Factor and Activates TrkB in Rodent Cortical Neurons: An Essential Step for Neuroprotection against Glutamate Excitotoxicity. Neuropharmacology, 43, 1173-1179. http://dx.doi.org/10.1016/S0028-3908(02)00217-4

[20] Castro, L.M., Gallant, M. and Niles, L.P. (2005) Novel Targets for Valproic Acid: Up-Regulation of Melatonin Receptors and Neurotrophic Factors in C6 Glioma Cells. Journal of Neurochemistry, 95, 1227-1236. http://dx.doi.org/10.1111/j.1471-4159.2005.03457.x

[21] Machado-Vieira, R., Dietrich, M.O., Leke, R., Cereser, V.H., Zanatto, V., Kapczinski, F., Souza, D.O., Portela, L.V. and Gentil, V. (2007) Decreased Plasma Brain Derived neurotrophic Factor Levels in Unmedicated Bipolar Patients during Manic Episode. Biological Psychiatry, 61, 142-144. http://dx.doi.org/10.1016/j.biopsych.2006.03.070

[22] Dowlatshahi, D., MacQueen, G., Wang, J.F., Chen, B. and Young, L.T. (2000) Increased Hippocampal Supragranular Timm Staining in Subjects with Bipolar Disorder. Neuroreport, 11, 3775-3778.

http://dx.doi.org/10.1097/00001756-200011270-00036 
Scientific Research Publishing (SCIRP) is one of the largest Open Access journal publishers. It is currently publishing more than 200 open access, online, peer-reviewed journals covering a wide range of academic disciplines. SCIRP serves the worldwide academic communities and contributes to the progress and application of science with its publication.

Other selected journals from SCIRP are listed as below. Submit your manuscript to us via either submit@scirp.org or Online Submission Portal.
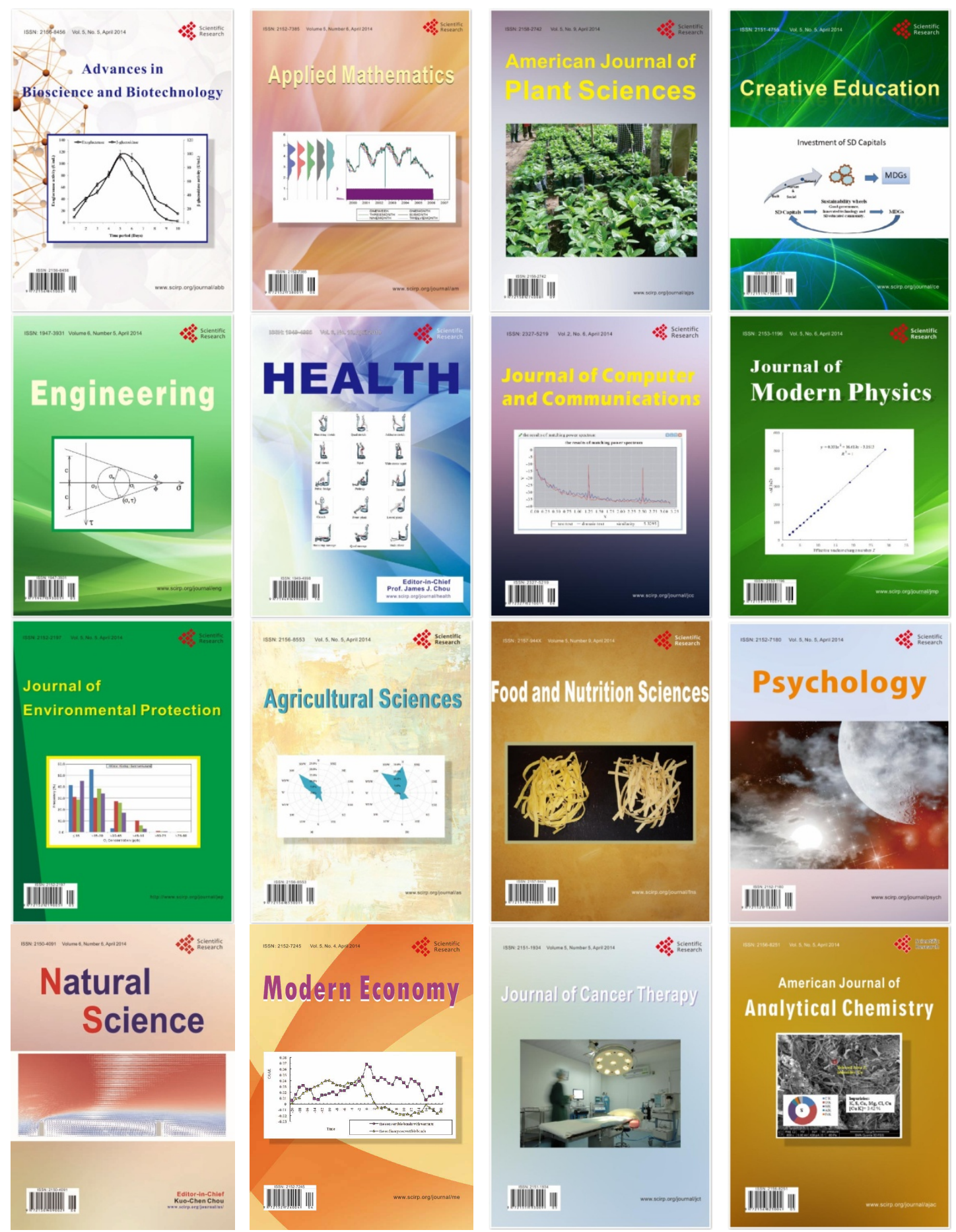